\title{
Adult sports-related traumatic brain injury in United States trauma centers
}

\author{
Ethan A. Winkler, MD, PhD,, John K. Yue, BA, 1,2 John F. Burke, MD, PhD, 1,2 \\ Andrew K. Chan, MD,,2 Sanjay S. Dhall, MD, ${ }^{1,2}$ Mitchel S. Berger, MD,1 \\ Geoffrey T. Manley, MD, PhD, ${ }^{1,2}$ and Phiroz E. Tarapore, MD ${ }^{1,2}$
}

'Department of Neurological Surgery, University of California, San Francisco; and ²Brain and Spinal Injury Center, San Francisco General Hospital, San Francisco, California

OBJECTIVE Sports-related traumatic brain injury (TBI) is an important public health concern estimated to affect 300,000 to 3.8 million people annually in the United States. Although injuries to professional athletes dominate the media, this group represents only a small proportion of the overall population. Here, the authors characterize the demographics of sports-related TBI in adults from a community-based trauma population and identify predictors of prolonged hospitalization and increased morbidity and mortality rates.

METHODS Utilizing the National Sample Program of the National Trauma Data Bank (NTDB), the authors retrospectively analyzed sports-related TBI data from adults (age $\geq 18$ years) across 5 sporting categories-fall or interpersonal contact (FIC), roller sports, skiing/snowboarding, equestrian sports, and aquatic sports. Multivariable regression analysis was used to identify predictors of prolonged hospital length of stay (LOS), medical complications, inpatient mortality rates, and hospital discharge disposition. Statistical significance was assessed at $\alpha<0.05$, and the Bonferroni correction for multiple comparisons was applied for each outcome analysis.

RESULTS From 2003 to 2012, in total, 4788 adult sports-related TBls were documented in the NTDB, which represented 18,310 incidents nationally. Equestrian sports were the greatest contributors to sports-related TBI (45.2\%). Mild TBI represented nearly $86 \%$ of injuries overall. Mean ( \pm SEM) LOSs in the hospital or intensive care unit (ICU) were $4.25 \pm$ 0.09 days and $1.60 \pm 0.06$ days, respectively. The mortality rate was $3.0 \%$ across all patients, but was statistically higher in TBI from roller sports (4.1\%) and aquatic sports (7.7\%). Age, hypotension on admission to the emergency department $(E D)$, and the severity of head and extracranial injuries were statistically significant predictors of prolonged hospital and ICU LOSs, medical complications, failure to discharge to home, and death. Traumatic brain injury during aquatic sports was similarly associated with prolonged ICU and hospital LOSs, medical complications, and failure to be discharged to home.

CONCLUSIONS Age, hypotension on ED admission, severity of head and extracranial injuries, and sports mechanism of injury are important prognostic variables in adult sports-related TBI. Increasing TBI awareness and helmet use-particularly in equestrian and roller sports-are critical elements for decreasing sports-related TBI events in adults.

http://thejns.org/doi/abs/10.3171/2016.1.FOCUS15613

KEY WORDS concussion; mortality; outcome; sports; traumatic brain injury

$\mathrm{T}$ RAUMATIC brain injury (TBI) is an alteration in brain function or other evidence of brain abnormality, resulting from an external force applied to the head. Traumatic brain injury occurs in several settings common to daily life, including recreational activities. ${ }^{21,25,30}$ In the United States, more than 2.5 million people seek medical care for TBI annually..$^{13}$ Underreporting of sports-related injuries, lack of consensus definitions, or limited recognition of milder injuries likely leads to gross underestimation of the true incidence of TBI. ${ }^{36}$ Approximately 70\%-90\% of all TBIs are comparatively mild and frequently given the colloquial term "concussion."” Emerging research

ABBREVIATIONS Charlson Comorbidity Index $=\mathrm{CCl} ; \mathrm{ED}=$ emergency department; $\mathrm{FIC}=$ fall or interpersonal contact; $\mathrm{GCS}=\mathrm{Glasgow}$ Coma Scale; ICD-9 = International Classification of Diseases, Ninth Revision; ICU = intensive care unit; ISS = Injury Severity Score; LOS = length of stay; NSP = National Sample Program; NTDB = National Trauma Data Bank; TBI = traumatic brain injury. SUBMITTED December 1, 2015. ACCEPTED January 19, 2016. INCLUDE WHEN CITING DOI: 10.3171/2016.1.FOCUS15613. 
suggests that even comparatively mild injury-especially when repetitive-is not without cognitive or neuropsychiatric consequences and may contribute to the development of neurodegeneration known as "chronic traumatic encephalopathy." $2,26-28,33,37$

With the growing recognition of the neurocognitive sequelae of head trauma, ${ }^{3,19,37}$ sports-related TBI has become an important public health concern. The exact annual incidence of sports-related TBI is unknown but is estimated to range from 300,000 to 3.8 million cases per year in the United States.11,15,21,29,41 Considerable attention has been focused on amateur and collegiate athletes of popular contact and inadvertent contact sports such as football, wrestling, ice hockey, rugby, soccer, baseball, and softball. ${ }^{12,16,34,45,48}$ Professional sports leagues-most notably the National Football League-have launched initiatives directed at the detection, prevention, and treatment of sports-related head injury. ${ }^{44}$ Brain injuries in professional athletes, however, represent only a small fraction of the overall incidence of TBI annually; the vast majority of these injuries occur in recreational athletes. The National Collegiate Athletic Association estimates that less than $1 \%$ of high school athletes go on to becoming professional athletes irrespective of the sports discipline. Given the increasing public awareness surrounding sports-related TBI, efforts are needed to characterize the mechanisms and morbidity and mortality rates of these injuries in the general population.

Here, we use the National Sample Program (NSP) of the National Trauma Data Bank (NTDB) - a registry that prospectively enrolls patients with the purpose of informing trauma care and outcome analyses in the United States. Data from 4788 adult sports-related head injuries collected from 2003 to 2012 were retrospectively analyzed to characterize the demographics, mortality rates, hospital length of stay (LOS), inpatient complications, and discharge disposition of adults with TBI sustained in several broad categories of sports-related injury. Patients in this registry are likely to have had more severe injuries, requiring transport to and treatment at a designated Level I or Level II trauma center.

Predictors of poor outcome were identified across different sports categories, which included fall or interpersonal contact (FIC), equestrian and related sports, roller sports, skiing/snowboarding, and aquatic sports. Our aim was to analyze and report the demographics of sports-related TBI in the adult population seen at trauma centers and to identify characteristics among patients and sports that influence overall morbidity and mortality rates in this age group.

\section{Methods}

The methods we used in this study are very similar to those used in the study by Yue et al., which appears in this issue of Neurosurgical Focus. To aid readers, we provide detailed descriptions in both papers. ${ }^{47}$

In this study, we used data in the NSP (https://www. facs.org/quality-programs/trauma/ntdb/nsp) of the NTDB from adult patients (age $\geq 18$ years) treated at the emergency department (ED) for sports-related TBI in a 10-year pe- riod (from 2003 to 2012). The NSP for each year consists of a stratified sample of 100 NTDB-participating hospitals, based on US census region, trauma care designation, and NTDB reporting status. The NTDB drew the hospitals from the sampling universe of 453 Level I or Level II trauma centers with the probability-proportional-tosize-sampling-without-replacement method of Levy and Lemeshow. A previous review determined that the sample size of 100 hospitals can be extrapolated to represent the national patient distribution. ${ }^{1}$ Detailed data qualification, selection, cleaning, and standardization algorithms have been previously reported. ${ }^{38}$ Because the NSP of the NTDB is a fully deidentified data set without the 18 federal Health Insurance Portability and Accountability Act identifiers, the current study was classified as being exempt from institutional review board review.

From 1,490,076 incidents contained in the overall NSP sample, data from adults who sustained a TBI were extracted as defined by the International Classification of Diseases, Ninth Revision (ICD-9) codes 800-801.99, 803-804.99, and 850-854.19 as previously described (Fig. 1). ${ }^{4,5,23}$ The subgroup with sports-related mechanisms of injury was included in the present analysis with ICD-9 Ecodes and stratified into the following 5 categories: FIC, roller sports (skateboarding and traditional roller skating), skiing/snowboarding, equestrian and related sports (i.e., equestrian and rodeo events), and aquatic sports (boating, swimming, diving, waterskiing, etc.) (Table 1). The ICD-9 E-codes in the NTDB do not identify individual sports, and the relative contributions of individual sports to each category are therefore unknown. The data of patients with known sex (variable name "gender"), ED Glasgow Coma Scale (GCS) score (variable name "edgcstotal"), and hospital discharge disposition (variable name "dischdisp" in NTDB 2003-2006; "hospdisp" in NTDB 2007-2012) were extracted. Seven patients who were noted to have died before hospital admission (variable name "eddisp" = "died," "died in ED") and 4 who had penetrating TBI (variable name "injurytype" = "penetrating") were excluded, yielding a final sample of 4788 cases.

Demographic and clinical variables of interest were extracted to include age, sex, race, health insurance status, medical history, mechanism of injury, scalar and stratified Injury Severity Score (ISS), ED discharge disposition, medical complications, hospital mortality rate, hospital discharge status, hospital LOS, intensive care unit (ICU) LOS, and days on ventilator. ${ }^{38}$ Medical comorbidity and complication rates were coded as present or absent, and the Charlson Comorbidity Index (CCI) was calculated with the standard comorbidity weights as previously described. ${ }^{9,46}$

Demographic and clinical variables that were missing or marked as not known or not recorded were coded as "unknown." Outcome analysis of mortality rates included all patients with a known hospital discharge status ( $\mathrm{n}=$ 4788). An analysis of hospital discharge to home included all patients with a known hospital discharge status, excluding death $(n=4644)$; these patients were dichotomized to "home, with or without services" versus "skilled nursing facility, rehabilitation, or other form of higher level care." Hospital and ICU LOSs analyses were performed with 


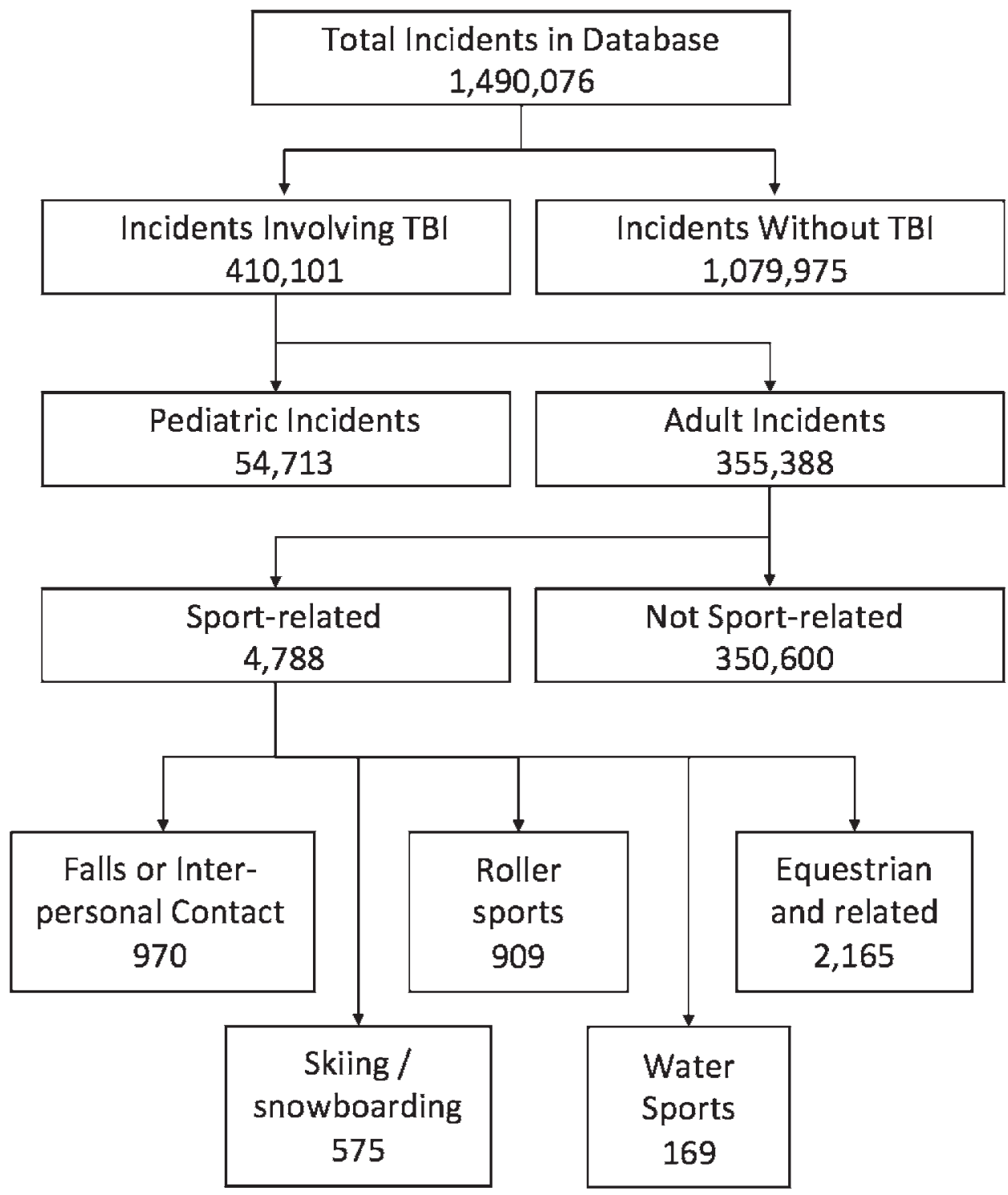

FIG. 1. Flow chart depicting the identification of sports-related TBI groups extracted from the NSP of the NTDB.

data from all patients who were alive at hospital discharge $(n=4640)$.

\section{Statistical Analysis}

Descriptive variables are presented as mean and SEM for continuous variables unless stated otherwise and as proportions for categorical variables. Statistical significance of differences among groups was assessed with ANOVA for continuous variables and with Pearson's chisquare test for categorical variables. For analyses with individual cell counts $<5$, Fisher's exact test was used in place of the chi-square test. Categorical outcome variables (presence of any inpatient complication, mortality rate, and hospital discharge to home) were assessed with binary logistic regression. Continuous outcome variables (hospital and ICU LOSs, and days on ventilator) were assessed with linear regression. All multivariable analyses were conducted with multivariable regression adjusted for the sports mechanism of injury (i.e., FIC, roller sports, skiing/snowboarding, equestrian and related sports, water sports, or other) and demographic and clinical variables (age, sex, race, health insurance, ED GCS score, stratified ISS, medical history of bleeding disorder, and CCI score).

Odds ratios with $95 \%$ CI are reported for all logistic regression models, and the mean increase or decrease values with $95 \%$ CI are reported for all linear regression models. Statistical significance was assessed at $\alpha=0.05$. The Bonferroni correction for multiple comparisons was applied in the 5 outcome analyses ( $\alpha=0.05$ divided by 5$)$, yielding a statistical significance threshold $\mathrm{p}=0.01$. All analyses were performed with SPSS version 22 (IBM Corporation).

\section{Results}

\section{Patient Demographics and Sports Injury Mechanisms}

For the 10-year period chosen for this study (2003- 
TABLE 1. Summary of extracted sports-related ICD-9 E-codes

\begin{tabular}{|c|c|c|}
\hline $\begin{array}{l}\text { Type of Sports } \\
\text { Injury \& Code }\end{array}$ & ICD9 E-Code Description & $\begin{array}{c}\text { No. of } \\
\text { Incidents }\end{array}$ \\
\hline FIC & & 970 \\
\hline 886.0 & Fall on same level from collision, pushing, or shoving, by or w/ other person in sports & 145 \\
\hline 917.0 & Striking against or struck accidentally by objects or persons in sports & 421 \\
\hline 917.5 & Striking against or struck accidentally by object in sports w/ subsequent fall & 404 \\
\hline Roller skate/skateboard & & 909 \\
\hline 885.1 & Fall from roller skates & 122 \\
\hline 885.2 & Fall from skateboard & 787 \\
\hline Ski/snowboard & & 575 \\
\hline 885.3 & Fall from skis & 255 \\
\hline 885.4 & Fall from snowboard & 320 \\
\hline Equestrian/related sports & & 2165 \\
\hline 828.2 & Accident involving animal being ridden injuring rider of animal & 2156 \\
\hline 828.9 & Accident involving animal being ridden injuring unspecified person & 9 \\
\hline Aquatic sports & & 169 \\
\hline 831.4 & Accident to watercraft causing other injury to water skier & 22 \\
\hline 831.5 & Accident to watercraft causing other injury to swimmer & 3 \\
\hline 832.4 & Other accidental submersion or drowning in water transport accident injuring water skier & 5 \\
\hline 832.5 & Other accidental submersion or drowning in water transport accident injuring swimmer & 0 \\
\hline 833.4 & Fall on stairs or ladders in water transport injuring water skier & 0 \\
\hline 833.5 & Fall on stairs or ladders in water transport injuring swimmer & 1 \\
\hline 883.0 & Accident from diving or jumping into water (swimming pool) & 100 \\
\hline 910.0 & Accidental drowning \& submersion while water-skiing & 5 \\
\hline 910.1 & $\begin{array}{l}\text { Accidental drowning \& submersion while engaged in other sport or recreational activity } \\
\text { w/ diving equipment }\end{array}$ & 1 \\
\hline 910.2 & $\begin{array}{l}\text { Accidental drowning \& submersion while engaged in other sport or recreational activity } \\
\text { w/o diving equipment }\end{array}$ & 32 \\
\hline
\end{tabular}

2012), the NSP recorded 355,388 incidents that resulted in TBI in adults. Traumatic brain injury resulting from the sports injury mechanisms included in this study accounted for 4788 events (Table 2), which corresponded to 18,310 events in the US population nationally, or roughly $1.3 \%$ of adult TBIs requiring admission to US trauma centers. The mean age $( \pm \mathrm{SD})$ of the cohort was $36.9 \pm 16.4$ years, and most patients were men (63.9\%) and white (79.9\%). Consistent with a younger and more active population, patients had, on average, few medical comorbidities, as evidenced by a mean CCI score of $0.2 \pm 0.5$ and a low prevalence of coagulopathy or needs for anticoagulant medications $(1.2 \%)$

Equestrian and related sports accounted for the greatest number of sports-related TBI (45.2\%), with FIC (20.3\%), roller sports (19.0\%), skiing/snowboarding (12.0\%), and aquatic sports $(3.5 \%)$ contributing to the remainder of the included injury mechanisms. The median initial GCS score was 15 (IQR 14-15), and the mean ISS was $12.9 \pm$ 8.1. Most patients $(85.6 \%)$ had mild TBI, and $3.6 \%$ and $10.6 \%$ had moderate and severe TBIs, respectively. Despite a predominance of mild TBI, more than $80 \%$ of those with TBI were admitted to the hospital: $40.9 \%$ to the general ward, $8.4 \%$ to telemetry-monitored units, and $33.9 \%$ to the ICU.
Those patients who were 18-29 years old disproportionately contributed to the number of sports-related TBIs and accounted for $44 \%$ of all events, and the relative contributions of each sports injury mechanism varied by age (Fig. 2). In those $18-29$ years old, roller sports (33\%) and FIC (26\%) contributed most to TBI. In the older subgroups, FIC and roller sports were less common injury mechanisms, reaching rates of approximately $9 \%$ and $4 \%$, respectively. Skiing/snowboarding injuries showed a similar trend from ages 18-59 years, but exhibited a small resurgence in patients older than 60 years. Conversely, equestrian and related sports showed age-dependent increases, increasing from $21 \%$ in those $18-29$ years to $71 \%$ in those 60 years or older. Aquatic sports contributed the least to the injuries in each age group and showed no significant age-specific trends.

\section{Inpatient Characteristics and Complications in Sports- Related TBI}

The mean hospital LOS across the different sports categories was $4.25 \pm 0.09$ days. Of these hospital stays and for all hospitalized patients, on average $1.60 \pm 0.06$ and $0.63 \pm 0.04$ days were spent in the ICU and on a ventilator, respectively. When those admitted to the ICU or on a mechanical ventilator were analyzed separately, the 
TABLE 2. Demographic data and injury characteristics of 4788 adults with sports-related $\mathrm{TBI}^{*}$

\begin{tabular}{|c|c|}
\hline Variable & Value $†$ \\
\hline Mean age in yrs (SD) & $36.9(16.4)$ \\
\hline M/F ratio (\%) & 3059 (63.9):1729 (36.1) \\
\hline Mean CCl score (SD) $\ddagger$ & $0.2(0.5)$ \\
\hline \multicolumn{2}{|l|}{ Race } \\
\hline White & $3824(79.9)$ \\
\hline Black & $171(3.6)$ \\
\hline Asian or Pacific Islander & $144(3.0)$ \\
\hline Native American & $20(0.4)$ \\
\hline Other & $287(6.0)$ \\
\hline Unknown & $342(7.1)$ \\
\hline \multicolumn{2}{|l|}{ Health insurance } \\
\hline Private/commercial & $1955(40.8)$ \\
\hline Medicare/Medicaid & $372(7.8)$ \\
\hline Government/other & $485(10.1)$ \\
\hline Self-pay/unbilled & $649(13.6)$ \\
\hline Unknown & $1327(27.7)$ \\
\hline \multicolumn{2}{|l|}{ Coagulopathy } \\
\hline No & $4728(98.7)$ \\
\hline Yes & $60(1.2)$ \\
\hline \multicolumn{2}{|l|}{ Injury mechanism } \\
\hline FIC & $970(20.3)$ \\
\hline Roller skate/skateboard & $909(19.0)$ \\
\hline Ski/snowboard & $575(12.0)$ \\
\hline Equestrian/related sports & $2165(45.2)$ \\
\hline Aquatic sports & $169(3.5)$ \\
\hline \multicolumn{2}{|l|}{ ED SBP } \\
\hline$<90$ & $133(2.8)$ \\
\hline$\geq 90$ & 4551 (95.1) \\
\hline Unknown & $104(2.2)$ \\
\hline \multicolumn{2}{|l|}{ ED GCS score } \\
\hline $3-8$ & $508(10.6)$ \\
\hline $9-12$ & $170(3.6)$ \\
\hline $13-15$ & $4110(85.8)$ \\
\hline \multicolumn{2}{|l|}{ ISS } \\
\hline $0-8$ & $1306(27.3)$ \\
\hline $9-15$ & $1100(23.0)$ \\
\hline $16-24$ & $1446(30.2)$ \\
\hline $25-75$ & $370(7.7)$ \\
\hline Unknown & $566(11.8)$ \\
\hline \multicolumn{2}{|l|}{ ED disposition } \\
\hline Home & $94(2.0)$ \\
\hline Observation & $124(2.6)$ \\
\hline General ward & $1956(40.9)$ \\
\hline Telemetry-monitored units & $402(8.4)$ \\
\hline ICU & $1625(33.9)$ \\
\hline OR & $270(5.6)$ \\
\hline Transfer & $2(0.0)$ \\
\hline Other/unknown & $315(6.6)$ \\
\hline
\end{tabular}

$\mathrm{OR}=$ operating room; $\mathrm{SBP}=$ systolic blood pressure.

* The age range of the patients was 18-87 years.

$\dagger$ Data represent number of patients (\%), unless indicated otherwise.

$\ddagger$ The range of the $\mathrm{CCl}$ score is $0-8$. mean ICU LOS was $4.17 \pm 0.15$ days, and the mean length of time on mechanical ventilation was $4.04 \pm 0.27$ days. Multivariable linear regression analyses identified identical predictors for prolonged LOSs in the hospital and ICU (Tables 3 and 4), that is, age, moderate or severe TBI (as indicated by GCS score), an ISS of 16-24 or 25-75, and sports injury mechanism. After multiple comparisons correction at a statistical significance threshold of $p=0.01$, skiing/snowboarding was associated with a nonsignificant statistical trend of shorter ICU LOS (mean decrease of 1.2 days, $95 \% \mathrm{CI}-2.2$ to -0.1 days, $\mathrm{p}=0.026$ ), but not shorter hospital LOS (mean decrease of 0.5 days, $95 \%$ CI -1.0 to 0.1 days, $\mathrm{p}=0.084$ ). Aquatic sports, on the other hand, were associated with a statistically significantly prolonged hospital LOS (mean increase 1.5 days, 95\% CI 0.6-2.4 days, $p=0.001$ ) and with a statistically nonsignificant trend of prolonged ICU LOS (mean increase 1.6 days, $95 \%$ CI 0.2-3.0 days, $\mathrm{p}=0.025$ ). No statistically significant associations were observed between the measured variables and the number of days of mechanical ventilation (data not shown).

In total, 259 patients $(5.4 \%)$ had medical complications during their hospital stay. These complications included acute kidney injury or renal failure, pneumonia, pulmonary embolism, acute respiratory distress syndrome, cardiac arrest, myocardial infarction, cerebrovascular accident, coagulopathy, decubitus ulceration, deep venous thrombosis, and urinary tract infection. Broken down by sports category, the complication rates were as follows: FIC 3.1\%, roller sports $5.9 \%$, skiing/snowboarding $5.4 \%$, equestrian and related sports $5.7 \%$, and aquatic sports $11.8 \%$.

Univariate statistical analysis confirmed that the differences observed in the complication rates for FIC and aquatic sports TBIs reached statistical significance $(\mathrm{p}<$ 0.05 ). Multivariable regression analysis indicated that age, sports mechanism of injury, moderate or severe TBI, and an ISS of $16-24,25-75$, or unknown were statistically significant predictors of medical complications (Table 5). Among the sports categories, an aquatic sports injury was associated with greater odds of complications (OR $3.7,95 \%$ CI $1.8-7.3, p<0.001)$ and appeared to be driving the statistically significant association with inpatient medical complications. A post hoc analysis suggested that this increased likelihood of complications was attributable to a higher prevalence of pulmonary diseases such as pneumonia $(8.5 \%, \mathrm{p}<0.001)$ and acute respiratory distress syndrome $(3.1 \%, \mathrm{p}=0.011)$ among those with $\mathrm{TBI}$ due to aquatic sports.

\section{Mortality Rates and Discharge Disposition}

We next sought to characterize the predictors of hospital discharge disposition and overall mortality rates. In total, 144 deaths occurred in the cohort as a result of sportsrelated TBI. This corresponded to a mortality rate of 3.0\% for sports-related TBI in patients presenting to a trauma center. For the individual sports categories, the mortality rates were as follows: FIC 2.3\%, roller sports 4.1\%, skiing/ snowboarding $2.1 \%$, equestrian and related sports $2.8 \%$, and aquatic sports $7.7 \%$.

Multivariable analyses indicated that age, sports mechanism of injury, severe TBI, and an ISS of 16-24, 25-75, or 

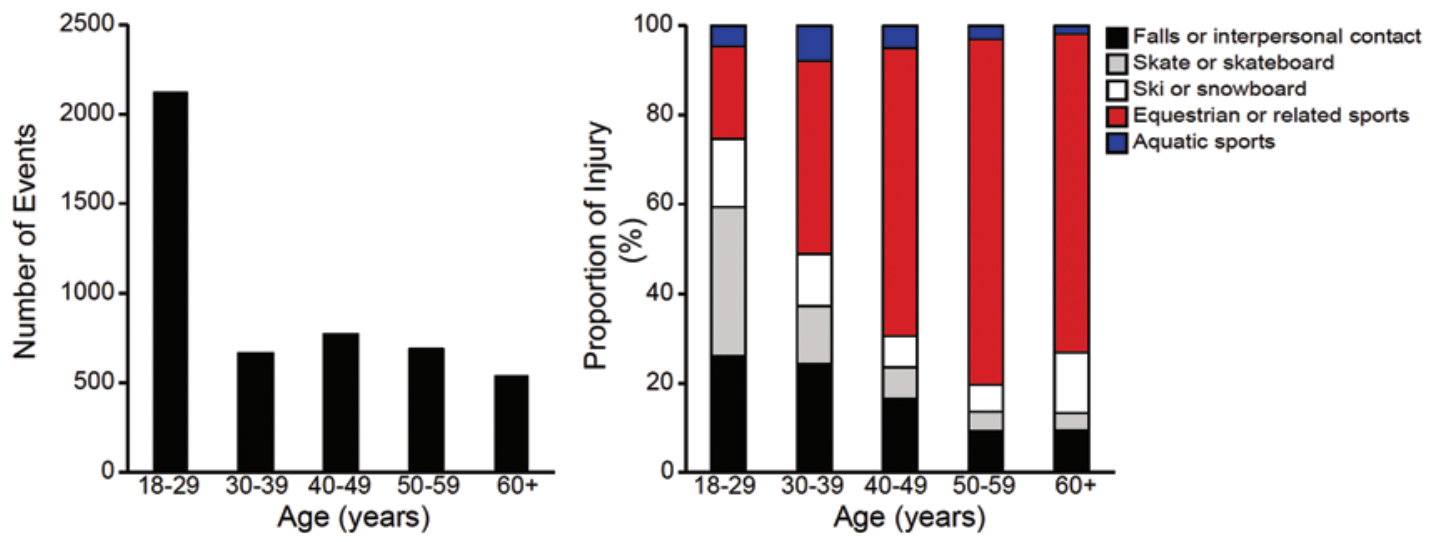

FIG. 2. Demographics of sports-related TBI by age and sports mechanism of injury. Left: Graph depicting the number of sportsrelated TBI events in each adult age group. Right: Graph depicting the proportions of sports-related TBI attributed to FIC, roller skating/skateboarding, skiing/snowboarding, equestrian and related sports, and aquatic sports in the 5 age groups.

unknown were statistically significant predictors of death (Table 6). Of note, after multiple comparisons correction (at a statistical significance threshold $\mathrm{p}=0.01$ ), this analysis indicated that a TBI incurred during roller sports was associated with a statistically nonsignificant trend for greater odds of death (OR 2.0, 95\% CI 1.0-4.1, p = 0.048). A similar but also statistically nonsignificant trend was observed for aquatic sports (OR 2.6, 95\% CI 1.0-6.6, $\mathrm{p}=0.053)$.

Among the patients who survived their injuries, 3943 $(84.9 \%)$ and $701(15.1 \%)$ were ultimately discharged to home and to rehabilitation or skilled nursing facilities, respectively. Across the sports categories, the rates of return to home were as follows: FIC $86.8 \%$, roller skating/skateboarding $86.1 \%$, skiing/snowboarding $84.0 \%$, equestrian and related sports $84.4 \%$, and aquatic sports $76.3 \%$. Univariate analysis indicated that the rate of return to home after an injury in aquatic sports was significantly lower than the return rates for the other sports injury mechanisms $(\mathrm{p}=0.009)$.

Multivariable logistic regression analysis indicated that age, presence of coagulopathy, ED hypotension, moderate or severe TBI, and an ISS of 16-24, 25-75, or unknown were significant predictors of diminished odds of returning home (Table 7). After multiple comparisons correction (threshold $\mathrm{p}=0.01$ ) with respect to the sports injury mechanism, aquatic sports were associated with a statistically nonsignificant trend of lower odds of return to home (OR $0.6,95 \%$ CI $0.4-1.0, \mathrm{p}=0.030$ ).

\section{Discussion}

Sports-related TBI is an important public health concern that has gained growing recognition by both the medical community and the lay public. Previous studies have reported on the incidence of sports-related TBI in various ED populations. ${ }^{10,17,39}$ However, the absence of inpatient and acute outcome data has precluded an analysis of hospital LOS, discharge disposition, and mortality rates after sports-related TBI. In the present analysis of an NTDB data set collected over a 10 -year interval, we characterized the demographic profiles, hospital and ICU LOSs, medical complications, mortality rates, and discharge disposition across multiple broad categories of sports disciplines in adults admitted for sports-related TBI to Level I and Level II US trauma centers. To our knowledge, this study is the first to characterize predictors of acute outcomes of adult sports-related TBI across several sports categories.

In our analysis of TBI in patients seen at Level I and Level II trauma centers, we found that mild TBI accounted for more than $80 \%$ of sports-related TBIs, a finding that is consistent with previous reports. ${ }^{39}$ The predictors of mortality rates in sports-related TBI were nearly identical to those identified in the Corticosteroid Randomization after Significant Head Injury (CRASH) and International Mission for Prognosis and Analysis of Clinical Trials in TBI (IMPACT) TBI prognostic models, that is, age, hypotension, GCS score, and presence of extracranial injury. $22,35,42$ Not surprisingly, these variables were also significantly associated with prolonged hospital and ICU LOSs and discharge disposition, suggesting that these prognostic models, although validated with cases of moderate and severe TBIs, likely also apply to patients with sports-related TBI. Whether including a sports-specific mechanism of injury improves the prognostic accuracy of these models in this population remains to be determined.

Across the sports categories analyzed, we noted several important trends. Equestrian and related sports were the largest contributor to sports-related TBI in adults and accounted for more than $50 \%$ of all TBIs in those older than 40 years. This finding is consistent with those in previous reports indicating greater rates of severe traumatic injury in equestrian and related sports than in other sports including football, rugby, and skiing. ${ }^{20,31,32,49}$ One report found that, when normalized for hours of activity, horseback riding results in a higher rate of hospital admission than other high-risk activities such as motorcycle riding. ${ }^{40}$ Interestingly, head injuries in equestrian and related sports were not associated with increased mortality rates, prolonged hospital LOS, or discharge disposition when compared with those incurred in other sports. Rates of helmet use are $25 \%$ or lower across equestrian sports, despite the fact that helmets have been associated with as much as a 40\%-50\% reduction in absolute risk for TBI. ${ }^{49}$ Thus, our work adds to the growing body of evidence highlighting the risks for TBI in equestrian sports. One clear approach for reducing 
TABLE 3. Multivariable analysis of LOS in the hospital after adult sports-related TBI

\begin{tabular}{|c|c|c|c|c|}
\hline Parameter & $B$ & SEM & $95 \% \mathrm{Cl}$ & p Value* \\
\hline \multicolumn{5}{|l|}{ Injury mechanism } \\
\hline FIC & Reference & NA & NA & NA \\
\hline Roller skate/skateboard & 0.4 & 0.2 & -0.105 to 0.9 & 0.077 \\
\hline Ski/snowboard & -0.5 & 0.3 & -1.0 to 0.1 & 0.084 \\
\hline Equestrian/related sports & 0.2 & 0.2 & -0.21 to 0.7 & 0.290 \\
\hline Aquatic sports & 1.5 & 0.4 & 0.6 to 2.4 & 0.001 \\
\hline Age (per-unit increase) & 0.02 & 0.0 & 0.01 to 0.03 & $<0.001$ \\
\hline CCI score (per-unit increase) & 0.2 & 0.2 & -0.1 to 0.5 & 0.200 \\
\hline \multicolumn{5}{|l|}{ Sex } \\
\hline Male & Reference & NA & NA & NA \\
\hline Female & -0.1 & 0.2 & -0.5 to 0.2 & 0.456 \\
\hline \multicolumn{5}{|l|}{ Race } \\
\hline White & Reference & NA & NA & NA \\
\hline Not white & 0.1 & 0.2 & -0.2 to 0.5 & 0.478 \\
\hline \multicolumn{5}{|l|}{ Health insurance } \\
\hline Private/commercial & Reference & NA & NA & NA \\
\hline Medicare/Medicaid & 0.3 & 0.3 & -0.3 to 0.9 & 0.339 \\
\hline Government/other & 0.0 & 0.3 & -0.5 to 0.6 & 0.950 \\
\hline Self-pay/unbilled & 0.2 & 0.2 & -0.3 to 0.7 & 0.436 \\
\hline Unknown & 0.3 & 0.2 & -0.1 to 0.6 & 0.146 \\
\hline \multicolumn{5}{|l|}{ Coagulopathy } \\
\hline No & Reference & NA & NA & NA \\
\hline Yes & 1.6 & 0.7 & 0.2 to 3.0 & 0.030 \\
\hline \multicolumn{5}{|l|}{ ED SBP } \\
\hline$\geq 90$ & Reference & NA & NA & NA \\
\hline$<90$ & 0.1 & 0.5 & -0.9 to 1.1 & 0.838 \\
\hline Unknown & 1.4 & 0.5 & 0.4 to 2.5 & 0.007 \\
\hline \multicolumn{5}{|l|}{ ED GCS score } \\
\hline $13-15$ & Reference & NA & NA & NA \\
\hline $9-12$ & 3.9 & 0.4 & $2.4-3.5$ & $<0.001$ \\
\hline $3-8$ & 7.6 & 0.3 & $7.0-8.2$ & $<0.001$ \\
\hline \multicolumn{5}{|l|}{ ISS } \\
\hline $0-8$ & Reference & NA & NA & NA \\
\hline $9-15$ & 1.2 & 0.2 & $0.7-1.6$ & $<0.001$ \\
\hline $16-24$ & 2.5 & 0.2 & $2.1-2.9$ & $<0.001$ \\
\hline $25-75$ & 7.9 & 0.4 & $7.2-8.6$ & $<0.001$ \\
\hline Unknown & 3.0 & 0.3 & $2.4-3.5$ & $<0.001$ \\
\hline
\end{tabular}

NA = not applicable.

* The statistical significance threshold was set at $p=0.01$ because we investigated 5 outcomes in the primary analysis.

the burden of TBI in this population is the promotion of helmet use.

The value of helmets in adult sports activities is further illustrated in a comparison of TBI due to roller sports with that due to skiing/snowboarding. Roller sports-related TBI, in our analysis, was associated with significantly increased odds of increased mortality rate, whereas skiing/snowboarding was not. Similarly, skiing/snowboarding TBI was associated with a shorter ICU LOS but not hospital LOS. Helmet use among skiers and snowboarders has been reported to exceed $70 \%$ and increases with each passing year., ${ }^{4,14}$ In contrast, helmet use in skateboarding is lower than $7 \%$, and $41.5 \%-75 \%$ of skateboarding accidents result in TBI. ${ }^{23,43}$ It seems reasonable to hypothesize that these differences in outcome between roller sports and skiing/snowboarding may in part reflect a difference in helmet use. Unfortunately, the NTDB did not capture helmet use consistently enough to test this hypothesis in our analysis.

In terms of overall numbers, aquatic sports were the smallest contributor to sports-related TBI, an observation that is in keeping with a previous report. ${ }^{39}$ Despite their low prevalence, TBIs due to aquatic sports were consistently associated with poor outcomes, including prolonged 
TABLE 4. Multivariable analysis of LOS in the ICU after adult sports-related TBI

\begin{tabular}{|c|c|c|c|c|}
\hline Parameter & B & SEM & $95 \% \mathrm{Cl}$ & $p$ Value* \\
\hline \multicolumn{5}{|l|}{ Injury mechanism } \\
\hline FIC & Reference & NA & NA & NA \\
\hline Roller skate/skateboard & 0.4 & 0.4 & -0.5 to 1.3 & 0.388 \\
\hline Ski/snowboard & -1.2 & 0.5 & -2.2 to -0.1 & 0.026 \\
\hline Equestrian/related sports & -0.1 & 0.4 & -1.0 to 0.7 & 0.769 \\
\hline Aquatic sports & 1.6 & 0.7 & 0.2 to 3.0 & 0.025 \\
\hline Age (per-unit increase) & 0.02 & 0.01 & 0.00 to 0.04 & 0.029 \\
\hline CCl score (per-unit increase) & 0.1 & 0.2 & -0.4 to 0.5 & 0.845 \\
\hline \multicolumn{5}{|l|}{ Sex } \\
\hline Male & Reference & NA & NA & NA \\
\hline Female & -0.2 & 0.3 & -0.9 to 0.4 & 0.471 \\
\hline \multicolumn{5}{|l|}{ Race } \\
\hline White & Reference & NA & NA & NA \\
\hline Not white & 0.2 & 0.4 & -0.6 to 0.8 & 0.683 \\
\hline \multicolumn{5}{|l|}{ Health insurance } \\
\hline Private/commercial & Reference & NA & NA & NA \\
\hline Medicare/Medicaid & 0.5 & 0.5 & -0.5 to 1.5 & 0.360 \\
\hline Government/other & -0.9 & 0.5 & -1.9 to 0.0 & 0.053 \\
\hline Self-pay/unbilled & -0.3 & 0.4 & -1.1 to 0.5 & 0.485 \\
\hline Unknown & 0.4 & 0.3 & -0.3 to 1.127 & 0.244 \\
\hline \multicolumn{5}{|l|}{ Coagulopathy } \\
\hline No & Reference & NA & NA & NA \\
\hline Yes & 1.3 & 1.0 & -0.7 to 3.3 & 0.188 \\
\hline \multicolumn{5}{|l|}{ ED SBP } \\
\hline$\geq 90$ & Reference & NA & NA & NA \\
\hline$<90$ & 0.8 & 1.3 & -1.7 to 3.4 & 0.513 \\
\hline Unknown & 1.4 & 0.9 & -0.4 to 3.2 & 0.114 \\
\hline \multicolumn{5}{|l|}{ ED GCS score } \\
\hline $13-15$ & Reference & NA & NA & NA \\
\hline $9-12$ & 2.8 & 0.5 & $1.8-3.8$ & $<0.001$ \\
\hline $3-8$ & 5.1 & 0.4 & $4.4-5.8$ & $<0.001$ \\
\hline \multicolumn{5}{|l|}{ ISS } \\
\hline $0-8$ & Reference & NA & NA & NA \\
\hline $9-15$ & 1.3 & 0.5 & $0.3-2.4$ & 0.013 \\
\hline $16-24$ & 2.4 & 0.5 & $1.5-3.4$ & $<0.001$ \\
\hline $25-75$ & 6.4 & 0.6 & $5.3-7.6$ & $<0.001$ \\
\hline Unknown & 3.5 & 0.6 & $2.4-4.6$ & $<0.001$ \\
\hline
\end{tabular}

* The statistical significance threshold was set at $p=0.01$ because we investigated 5 outcomes in the primary analysis.

hospital and ICU LOSs, higher rates of medical complications, diminished odds of return to home, and a strong, statistically significant trend toward increased mortality rate that likely failed to reach significance because of the small sample size. We hypothesize that patients who had an aquatic sports-related TBI are at increased risk for submersion after an injury, which predisposes them to aspiration. Such patients therefore exhibit higher rates of pulmonary complications, anoxic injury (in cases of drowning or near drowning), and hypothermia. ${ }^{18}$ Jumping or diving into a swimming pool accounts for the greatest number of water sports-related TBI. Therefore, we urge increased awareness about the dangers of these activities in and around the swimming pool. Although previous efforts have investigated cervical spinal cord injuries in aquatic sports, ${ }^{8}$ no dedicated studies of TBI have yet been conducted, and our findings suggest that additional studies of the complications and of morbidity and mortality rates involving aquatic sports and TBI are warranted.

\section{Limitations}

This study is not without limitations. The analysis included only sports-related TBI of patients who presented to US Level I and Level II trauma centers participating in 
TABLE 5. Multivariable analysis of predictors of medical complications after adult sports-related TBI

\begin{tabular}{|c|c|c|}
\hline Parameter & Odds Ratio $(95 \% \mathrm{Cl})$ & p Value* \\
\hline Injury mechanism & & 0.006 \\
\hline FIC & Reference & NA \\
\hline Roller skate/skateboard & $1.4(0.8-2.3)$ & 0.217 \\
\hline Ski/snowboard & $1.2(0.7-2.2)$ & 0.491 \\
\hline Equestrian/related sports & $1.4(0.8-2.3)$ & 0.189 \\
\hline Aquatic sports & $3.7(1.8-7.3)$ & $<0.001$ \\
\hline Age (per-unit increase) & $1.01(1.00-1.03)$ & 0.009 \\
\hline CCl score (per-unit increase) & $1.2(0.9-1.4)$ & 0.172 \\
\hline \multicolumn{3}{|l|}{ Sex } \\
\hline Male & Reference & NA \\
\hline Female & $0.9(0.6-1.2)$ & 0.374 \\
\hline \multicolumn{3}{|l|}{ Race } \\
\hline White & Reference & NA \\
\hline Not white & $1.2(0.8-1.7)$ & 0.424 \\
\hline Health insurance & & 0.027 \\
\hline Private/commercial & Reference & NA \\
\hline Medicare/Medicaid & $0.8(0.5-1.4)$ & 0.537 \\
\hline Government/other & $0.5(0.3-0.9)$ & 0.014 \\
\hline Self-pay/unbilled & $0.5(0.3-0.8)$ & 0.008 \\
\hline Unknown & $0.8(0.6-1.2)$ & 0.277 \\
\hline \multicolumn{3}{|l|}{ Coagulopathy } \\
\hline No & Reference & NA \\
\hline Yes & $2.3(1.0-5.3)$ & 0.057 \\
\hline ED SBP & & 0.174 \\
\hline$\geq 90$ & Reference & NA \\
\hline$<90$ & $0.8(0.3-1.6)$ & 0.468 \\
\hline Unknown & $1.9(0.9-3.9)$ & 0.090 \\
\hline ED GCS score & & $<0.001$ \\
\hline $13-15$ & Reference & NA \\
\hline $9-12$ & $8.6(5.3-14.1)$ & $<0.001$ \\
\hline $3-8$ & $13.6(9.9-18.7)$ & $<0.001$ \\
\hline ISS & & $<0.001$ \\
\hline $0-8$ & Reference & NA \\
\hline $9-15$ & $1.8(0.9-3.6)$ & 0.119 \\
\hline $16-24$ & $4.4(2.4-8.1)$ & $<0.001$ \\
\hline $25-75$ & $8.5(4.5-16.2)$ & $<0.001$ \\
\hline Unknown & $5.9(3.1-11.2)$ & $<0.001$ \\
\hline
\end{tabular}

* The statistical significance threshold was set at $p=0.01$ because we investigated 5 outcomes in the primary analysis.

the NTDB. It therefore captured only the most severe injuries, that is, those that required care in tertiary care hospitals. Consequently, our analysis did not include unreported sports-related TBI, nor did it capture injuries incurred through mechanisms that fall outside the coding parameters of the NTDB. We therefore expect that our analysis of sports-related TBI did not estimate its true prevalence, which is likely several times that of our reported number of injuries.

The NSP of the NTDB is a large prospectively enroll-
TABLE 6. Multivariable analysis of predictors of death after adult sports-related TBI

\begin{tabular}{|c|c|c|}
\hline Parameter & Odds Ratio $(95 \% \mathrm{Cl})$ & p Value* \\
\hline Injury mechanism & & $<0.001$ \\
\hline FIC & Reference & NA \\
\hline Roller skate/skateboard & $2.0(1.0-4.1)$ & 0.048 \\
\hline Ski/snowboard & $0.4(0.2-1.1)$ & 0.071 \\
\hline Equestrian/related sports & $0.8(0.4-1.5)$ & 0.433 \\
\hline Aquatic sports & $2.6(1.0-6.6)$ & 0.053 \\
\hline Age (per-unit increase) & $1.03(1.02-1.05)$ & $<0.001$ \\
\hline $\mathrm{CCl}$ score (per-unit increase) & $1.1(0.7-1.6)$ & 0.718 \\
\hline \multicolumn{3}{|l|}{ Sex } \\
\hline Male & Reference & NA \\
\hline Female & $0.7(0.4-1.1)$ & 0.125 \\
\hline \multicolumn{3}{|l|}{ Race } \\
\hline White & Reference & NA \\
\hline Not white & $0.8(0.4-1.4)$ & 0.378 \\
\hline Health insurance & & 0.030 \\
\hline Private/commercial & Reference & NA \\
\hline Medicare/Medicaid & $2.0(1.0-4.1)$ & 0.066 \\
\hline Government/other & $1.6(0.8-3.3)$ & 0.216 \\
\hline Self-pay/unbilled & $2.2(1.2-4.1)$ & 0.015 \\
\hline Unknown & $2.2(1.3-3.8)$ & $<0.001$ \\
\hline \multicolumn{3}{|l|}{ Coagulopathy } \\
\hline No & Reference & NA \\
\hline Yes & $2.8(0.9-9.2)$ & 0.084 \\
\hline ED SBP & & $<0.001$ \\
\hline$\geq 90$ & Reference & NA \\
\hline$<90$ & $5.2(2.3-11.7)$ & $<0.001$ \\
\hline Unknown & $1.2(0.4-3.5)$ & 0.810 \\
\hline ED GCS score & & $<0.001$ \\
\hline $13-15$ & Reference & NA \\
\hline $9-12$ & $2.9(0.9-9.1)$ & 0.067 \\
\hline $3-8$ & $30.5(18.1-51.6)$ & $<0.001$ \\
\hline ISS & & $<0.001$ \\
\hline $0-8$ & Reference & NA \\
\hline $9-15$ & $4.9(0.6-42.6)$ & 0.153 \\
\hline $16-24$ & $14.0(1.9-105.2)$ & 0.010 \\
\hline $25-75$ & $77.8(10.5-578.7)$ & $<0.001$ \\
\hline Unknown & $26.1(3.4-199.1)$ & $<0.001$ \\
\hline
\end{tabular}

* The statistical significance threshold was set at $p=0.01$ because we investigated 5 outcomes in the primary analysis.

ing database. However, patients are enrolled on a volitional basis through convenience sampling, which may introduce bias into the data set. All analyses are retrospective and may be skewed by inaccurate or missing data. Underreporting of TBI-related ICD-9 E-codes may have caused underestimation of their prevalence in our descriptive statistics. Similarly, the ICD-9 E-codes in the NTDB do not permit identifying individual sports. Given the currently heightened scrutiny of an association between football and TBI, additional details about specific sports disciplines 
TABLE 7. Multivariable analysis of predictors of hospital discharge disposition after adult sports-related TBI

\begin{tabular}{|c|c|c|}
\hline Parameter & Odds Ratio $(95 \% \mathrm{Cl})$ & p Value* \\
\hline Injury mechanism & & 0.113 \\
\hline FIC & Reference & NA \\
\hline Roller skate/skateboard & $1.0(0.7-1.3)$ & 0.763 \\
\hline Ski/snowboard & $1.0(0.7-1.4)$ & 0.982 \\
\hline Equestrian/related sports & $1.1(0.8-1.5)$ & 0.461 \\
\hline Aquatic sports & $0.6(0.4-1.0)$ & 0.030 \\
\hline Age (per-unit increase) & $0.98(0.98-0.99)$ & $<0.001$ \\
\hline CCl score (per-unit increase) & $1.0(0.9-1.2)$ & 0.968 \\
\hline \multicolumn{3}{|l|}{ Sex } \\
\hline Male & Reference & NA \\
\hline Female & $1.0(0.8-1.2)$ & 0.945 \\
\hline \multicolumn{3}{|l|}{ Race } \\
\hline White & Reference & NA \\
\hline Not white & $0.8(0.6-1.0)$ & 0.066 \\
\hline Health insurance & & 0.110 \\
\hline Private/commercial & Reference & NA \\
\hline Medicare/Medicaid & $0.8(0.6-1.2)$ & 0.318 \\
\hline Government/other & $0.8(0.6-1.1)$ & 0.110 \\
\hline Self-pay/unbilled & $1.0(0.7-1.3)$ & 0.886 \\
\hline Unknown & $1.2(0.9-1.5)$ & 0.172 \\
\hline \multicolumn{3}{|l|}{ Coagulopathy } \\
\hline No & Reference & NA \\
\hline Yes & $0.4(0.2-0.8)$ & 0.012 \\
\hline ED SBP & & $<0.001$ \\
\hline$\geq 90$ & Reference & NA \\
\hline$<90$ & $0.08(0.05-0.12)$ & $<0.001$ \\
\hline Unknown & $0.8(0.4-1.3)$ & 0.311 \\
\hline ED GCS score & & $<0.001$ \\
\hline $13-15$ & Reference & NA \\
\hline $9-12$ & $0.3(0.2-0.4)$ & $<0.001$ \\
\hline $3-8$ & $0.2(0.1-0.2)$ & $<0.001$ \\
\hline ISS & & $<0.001$ \\
\hline $0-8$ & Reference & NA \\
\hline $9-15$ & $0.8(0.6-1.0)$ & 0.091 \\
\hline $16-24$ & $0.5(0.4-0.6)$ & $<0.001$ \\
\hline $25-75$ & $0.2(0.1-0.2)$ & $<0.001$ \\
\hline Unknown & $0.4(0.3-0.6)$ & $<0.001$ \\
\hline
\end{tabular}

* The statistical significance threshold was set at $p=0.01$ because we investigated 5 outcomes in the primary analysis.

would have been helpful for comparing contact sports with noncontact sports. Despite these limitations, the NTDB has been extensively used to elucidate the epidemiology of different traumatic injuries and is the most comprehensive trauma database available for Level I and Level II trauma centers.

\section{Conclusions}

Age, hypotension, severity of head and extracranial injuries, and sports mechanism of injury were important prognostic variables in adult sports-related TBI observed at Level I and Level II trauma centers. Increasing TBI awareness and helmet use-particularly in equestrian and roller sports-are critical elements for reducing sportsrelated TBI in adults. The category of aquatic sports was an independent predictor of poor outcome after TBI via an increased risk for pulmonary complication. Increased age was a strong predictor for TBI in equestrian and related sports. Understanding the characteristics of sports-related TBI in terms of complication, morbidity, and mortality rates may help focus public awareness on efforts to reduce the incidence of these debilitating injuries.

\section{Acknowledgments}

We acknowledge the use of the NSP in this study as follows: Committee on Trauma, American College of Surgeons, NTDB NSP 2003-12, Chicago, IL. The content reproduced from the NTDB NSP remains the full and exclusive copyrighted property of the American College of Surgeons. The American College of Surgeons is not responsible for any claims arising from works based on the original data, text, tables, or figures.

\section{References}

1. American College of Surgeons: National Trauma Data Bank (NTDB) National Sample Program, Arrival Year 2012 (January, 2013). Instructional Manual. (https://www. facs.org/ /media/files/quality\%20programs/trauma/ntdb/ ntdbmanual2012.ashx) [Accessed March 4, 2016]

2. Arciniegas DB, Anderson CA, Topkoff J, McAllister TW: Mild traumatic brain injury: a neuropsychiatric approach to diagnosis, evaluation, and treatment. Neuropsychiatr Dis Treat 1:311-327, 2005

3. Bailes JE, Petraglia AL, Omalu BI, Nauman E, Talavage T: Role of subconcussion in repetitive mild traumatic brain injury. J Neurosurg 119:1235-1245, 2013

4. Baschera D, Hasler RM, Taugwalder D, Exadaktylos A, Raabe A: Association between head injury and helmet use in alpine skiers: cohort study from a Swiss level 1 trauma center. J Neurotrauma 32:557-562, 2015

5. Bekelis K, Missios S, Mackenzie TA: Prehospital helicopter transport and survival of patients with traumatic brain injury. Ann Surg 261:579-585, 2015

6. Bowman SM, Martin DP, Sharar SR, Zimmerman FJ: Racial disparities in outcomes of persons with moderate to severe traumatic brain injury. Med Care 45:686-690, 2007

7. Cassidy JD, Carroll LJ, Peloso PM, Borg J, von Holst H, Holm L, et al: Incidence, risk factors and prevention of mild traumatic brain injury: results of the WHO Collaborating Centre Task Force on Mild Traumatic Brain Injury. J Rehabil Med 43 Suppl:28-60, 2004

8. Chang SK, Tominaga GT, Wong JH, Weldon EJ, Kaan KT: Risk factors for water sports-related cervical spine injuries. J Trauma 60:1041-1046, 2006

9. Charlson ME, Pompei P, Ales KL, MacKenzie CR: A new method of classifying prognostic comorbidity in longitudinal studies: development and validation. J Chronic Dis 40:373383,1987

10. Coronado VG, Haileyesus T, Cheng TA, Bell JM, HaarbauerKrupa J, Lionbarger MR, et al: Trends in Sports- and Recreation-Related Traumatic Brain Injuries Treated in US Emergency Departments: The National Electronic Injury Surveillance System-All Injury Program (NEISS-AIP) 2001-2012. J Head Trauma Rehabil 30:185-197, 2015

11. Daneshvar DH, Nowinski CJ, McKee AC, Cantu RC: The epidemiology of sport-related concussion. Clin Sports Med 30:1-17, vii, 2011 
12. Dompier TP, Kerr ZY, Marshall SW, Hainline B, Snook EM, Hayden R, et al: Incidence of concussion during practice and games in youth, high school, and collegiate American football players. JAMA Pediatr 169:659-665, 2015

13. Faul M, Xu L, Wald MM, Coronado VG: Traumatic Brain Injury in the United States: Emergency Department Visits, Hospitalizations and Deaths, 2002-2006. Atlanta: Centers for Disease Control and Prevention, National Center for Injury, 2010

14. Fenerty L, Thibault-Halman G, Bruce BS, Landry J, Young J, Walling S, et al: Helmets for skiing and snowboarding: who is using them and why. J Trauma Acute Care Surg 74:895900,2013

15. Gessel LM, Fields SK, Collins CL, Dick RW, Comstock RD: Concussions among United States high school and collegiate athletes. J Athl Train 42:495-503, 2007

16. Giza CC, Kutcher JS, Ashwal S, Barth J, Getchius TS, Gioia GA, et al: Summary of evidence-based guideline update: evaluation and management of concussion in sports: report of the Guideline Development Subcommittee of the American Academy of Neurology. Neurology 80:2250-2257, 2013

17. Haring RS, Canner JK, Asemota AO, George BP, Selvarajah S, Haider AH, et al: Trends in incidence and severity of sports-related traumatic brain injury (TBI) in the emergency department, 2006-2011. Brain Inj 29:989-992, 2015

18. Ibsen LM, Koch T: Submersion and asphyxial injury. Crit Care Med 30 (11 Suppl):S402-S408, 2002

19. Jordan BD: The clinical spectrum of sport-related traumatic brain injury. Nat Rev Neurol 9:222-230, 2013

20. Kriss TC, Kriss VM: Equine-related neurosurgical trauma: a prospective series of 30 patients. J Trauma 43:97-99, 1997

21. Langlois JA, Rutland-Brown W, Wald MM: The epidemiology and impact of traumatic brain injury: a brief overview. J Head Trauma Rehabil 21:375-378, 2006

22. Lingsma H, Andriessen TM, Haitsema I, Horn J, van der Naalt J, Franschman G, et al: Prognosis in moderate and severe traumatic brain injury: external validation of the IMPACT models and the role of extracranial injuries. J Trauma Acute Care Surg 74:639-646, 2013

23. Lustenberger T, Talving P, Barmparas G, Schnüriger B, Lam L, Inaba K, et al: Skateboard-related injuries: not to be taken lightly. A National Trauma Databank Analysis. J Trauma 69:924-927, 2010

24. Majidi S, Siddiq F, Qureshi AI: Prehospital neurologic deterioration is independent predictor of outcome in traumatic brain injury: analysis from National Trauma Data Bank. Am J Emerg Med 31:1215-1219, 2013

25. Manley GT, Maas AI: Traumatic brain injury: an international knowledge-based approach. JAMA 310:473-474, 2013

26. McCrea M, Iverson GL, McAllister TW, Hammeke TA, Powell MR, Barr WB, et al: An integrated review of recovery after mild traumatic brain injury (MTBI): implications for clinical management. Clin Neuropsychol 23:1368-1390, 2009

27. McKee AC, Cantu RC, Nowinski CJ, Hedley-Whyte ET, Gavett $\mathrm{BE}$, Budson $\mathrm{AE}$, et al: Chronic traumatic encephalopathy in athletes: progressive tauopathy after repetitive head injury. J Neuropathol Exp Neurol 68:709-735, 2009

28. McKee AC, Stern RA, Nowinski CJ, Stein TD, Alvarez VE, Daneshvar DH, et al: The spectrum of disease in chronic traumatic encephalopathy. Brain 136:43-64, 2013

29. Meehan WP III, d'Hemecourt P, Comstock RD: High school concussions in the 2008-2009 academic year: mechanism, symptoms, and management. Am J Sports Med 38:24052409, 2010

30. Menon DK, Schwab K, Wright DW, Maas AI: Position statement: definition of traumatic brain injury. Arch Phys Med Rehabil 91:1637-1640, 2010

31. Norwood S, McAuley C, Vallina VL, Fernandez LG, McLar- ty JW, Goodfried G: Mechanisms and patterns of injuries related to large animals. J Trauma 48:740-744, 2000

32. Paix BR: Rider injury rates and emergency medical services at equestrian events. Br J Sports Med 33:46-48, 1999

33. Ponsford J, Draper K, Schönberger M: Functional outcome 10 years after traumatic brain injury: its relationship with demographic, injury severity, and cognitive and emotional status. J Int Neuropsychol Soc 14:233-242, 2008

34. Powell JW, Barber-Foss KD: Traumatic brain injury in high school athletes. JAMA 282:958-963, 1999

35. Roozenbeek B, Lingsma HF, Lecky FE, Lu J, Weir J, Butcher I, et al: Prediction of outcome after moderate and severe traumatic brain injury: external validation of the International Mission on Prognosis and Analysis of Clinical Trials (IMPACT) and Corticoid Randomisation After Significant Head injury (CRASH) prognostic models. Crit Care Med 40:1609-1617, 2012

36. Roozenbeek B, Maas AI, Menon DK: Changing patterns in the epidemiology of traumatic brain injury. Nat Rev Neurol 9:231-236, 2013

37. Saigal R, Berger MS: The long-term effects of repetitive mild head injuries in sports. Neurosurgery 75 (Suppl 4):S149S155, 2014

38. Schoenfeld AJ, Belmont PJ Jr, See AA, Bader JO, Bono CM: Patient demographics, insurance status, race, and ethnicity as predictors of morbidity and mortality after spine trauma: a study using the National Trauma Data Bank. Spine J 13:1766-1773, 2013

39. Selassie AW, Wilson DA, Pickelsimer EE, Voronca DC, Williams NR, Edwards JC: Incidence of sport-related traumatic brain injury and risk factors of severity: a population-based epidemiologic study. Ann Epidemiol 23:750-756, 2013

40. Sorli JM: Equestrian injuries: a five year review of hospital admissions in British Columbia, Canada. Inj Prev 6:59-61, 2000

41. Sosin DM, Sniezek JE, Thurman DJ: Incidence of mild and moderate brain injury in the United States, 1991. Brain Inj 10:47-54, 1996

42. Steyerberg EW, Mushkudiani N, Perel P, Butcher I, Lu J, McHugh GS, et al: Predicting outcome after traumatic brain injury: development and international validation of prognostic scores based on admission characteristics. PLoS Med 5:e165, 2008

43. Tominaga GT, Schaffer KB, Dandan IS, Coufal FJ, Kraus JF: Head injuries in hospital-admitted adolescents and adults with skateboard-related trauma. Brain Inj 29:1044-1050, 2015

44. Underwood E: Neuroscience. NFL kicks off brain injury research effort. Science 339:1367, 2013

45. Wasserman EB, Kerr ZY, Zuckerman SL, Covassin T: Epidemiology of sports-related concussions in National Collegiate Athletic Association athletes from 2009-2010 to 2013-2014: symptom prevalence, symptom resolution time, and returnto-play time. Am J Sports Med 44:226-233, 2016

46. Winkler EA, Yue JK, Birk H, Robinson CK, Manley GT, Dhall SS, et al: Perioperative morbidity and mortality after lumbar trauma in the elderly. Neurosurg Focus 39(4):E2, 2015

47. Yue JK, Winkler EA, Burke JF, Chan AK, Dhall SS, Berger MS, et al: Pediatric sports-related traumatic brain injury in United States trauma centers. Neurosurg Focus 40(4):E3, 2016

48. Zuckerman SL, Kerr ZY, Yengo-Kahn A, Wasserman E, Covassin T, Solomon GS: Epidemiology of sports-related concussion in NCAA athletes from 2009-2010 to 2013-2014: incidence, recurrence, and mechanisms. Am J Sports Med 43:2654-2662, 2015

49. Zuckerman SL, Morgan CD, Burks S, Forbes JA, Chambless LB, Solomon GS, et al: Functional and structural traumatic 
brain injury in equestrian sports: a review of the literature. World Neurosurg 83:1098-1113,2015

\section{Disclosures}

The authors report no conflict of interest concerning the materials or methods used in this study or the findings specified in this paper.

\section{Author Contributions}

Conception and design: Tarapore, Winkler, Yue. Acquisition of data: Winkler, Yue, Chan. Analysis and interpretation of data:
Winkler, Yue. Drafting the article: Tarapore, Winkler, Yue, Burke, Chan. Critically revising the article: Tarapore, Winkler, Burke, Dhall, Berger, Manley. Reviewed submitted version of manuscript: Tarapore, Winkler, Dhall, Berger. Approved the final version of the manuscript on behalf of all authors: Tarapore. Statistical analysis: Tarapore, Winkler, Yue. Study supervision: Tarapore, Berger, Manley.

\section{Correspondence}

Phiroz E. Tarapore, San Francisco General Hospital, 1001 Potrero Ave., Bldg. 1, Rm. 101, San Francisco, CA 94110. email: taraporep@neurosurg.ucsf.edu. 